\title{
A Review for the Practicing Clinician: Hepatorenal Syndrome, a Form of Acute Kidney Injury, in Patients with Cirrhosis
}

\author{
Amanda Chaney \\ Department of Transplant, College of \\ Medicine, Mayo Clinic, Jacksonville, \\ FL, USA
}

\begin{abstract}
The hepatorenal syndrome type of acute kidney injury (HRS-AKI), formerly known as type 1 hepatorenal syndrome, is a rapidly progressing renal failure that occurs in many patients with advanced cirrhosis and ascites. Accumulating evidence has led to a recent evolution of diagnostic criteria for this serious complication of end-stage liver disease. The aim of this review is to provide an overview of disease-related characteristics and therapeutic management of patients with HRS-AKI. Relevant literature was compiled to support discussion of the pathophysiology, diagnosis, prognosis, associated conditions, prevention, treatment, and management of HRS-AKI. Onset of HRS-AKI is characterized by sudden severe renal vasoconstriction, leading to an acute reduction in glomerular filtration rate and rapid, potentially life-threatening, renal deterioration. Although our understanding of disease pathophysiology continues to evolve, etiology of HRS-AKI likely involves systemic hemodynamic changes caused by liver disease, inflammation, and damage to renal parenchyma. There is currently no gold standard for diagnosis, which typically involves a clinical workup, abdominal imaging, and laboratory assessments. The current consensus definition of HRSAKI includes proposed diagnostic criteria based on changes in serum creatinine levels tailored for high sensitivity, and rapid detection to accelerate diagnosis and treatment initiation. The only potential cure for HRS-AKI is liver transplantation; however, vasoconstrictive agents and other supportive measures are used as needed to help maintain survival for patients who are awaiting or are ineligible for transplantation. The severity of HRS-AKI, complex pathology, limited treatment options, and range of associated conditions pose significant challenges for both patients and care providers.
\end{abstract}

Keywords: ascites, hepatorenal syndrome, liver transplantation, cirrhosis, portal hypertension

\section{Introduction}

Hepatorenal syndrome (HRS) is a type of renal failure that can occur in patients with advanced cirrhosis and associated ascites, circulatory dysfunction, and acute liver failure. ${ }^{1,2}$ HRS is the only known renal failure exclusively caused by liver disease, distinguishing it from other renal conditions associated with liver failure such as prerenal azotemia and acute tubular necrosis. ${ }^{3}$

Until recently, HRS was categorized into 2 major types: the severe and rapidly progressing form of HRS (formerly called HRS type 1 [HRS-1]) marked by cirrhosis with ascites, and the milder, more slowly progressing form of HRS (formerly called HRS type 2 [HRS-2]) that is typically associated with refractory
Correspondence: Amanda Chaney Department of Transplant, College of Medicine, Mayo Clinic, 4500 San Pablo Road, Jacksonville, FL, 32224, USA

Tel + | 904-956-3346

Fax + 904-956-3359

Email chaney.amanda@mayo.edu 
ascites. $^{2,4}$ Diagnostic criteria for acute renal failure in HRS-1 have evolved over time., ${ }^{2,45}$ Accumulating evidence and advances in the field of nephrology prompted the International Club of Ascites to reclassify HRS-1 as the hepatorenal syndrome type of acute kidney injury (HRS-AKI) in 2015, and HRS-2 as HRS-NAKI (nonAKI) in 2019. ${ }^{5-7}$ The new definition of HRS-AKI removed prior criteria that required diagnosis to be established at an advanced stage of acute kidney injury (AKI), facilitating an earlier diagnosis and initiation of treatment (Table 1). ${ }^{6}$ These new classifications have shown that HRS-AKI develops in $27 \%$ to $53 \%$ of patients with cirrhosis who are admitted to the hospital, and that inhospital mortality and post-liver transplant mortality directly correlate with the severity of AKI. ${ }^{8}$ Although the new definition of HRS-AKI is likely to help improve patient care by accelerating diagnosis, treatment, and management, it also requires a shift in how we interpret historic clinical and epidemiologic data based on the old definitions of HRS-1.

\section{Disease Characteristics}

HRS-AKI is associated with a high mortality rate $^{7}$ and can occur due to a precipitating event like bacterial infection and/ or following acute liver injury stemming from causes such as alcohol abuse, drug use, hypovolemia from overuse of diuretics, and exacerbations of viral hepatitis. ${ }^{9}$ The cause of HRSAKI greatly influences the outcome of the disease and is a factor for survival, with bacterial infections corresponding with the worst outcomes. ${ }^{8}$ While prevalence estimates for HRS-AKI vary widely, this condition has been reported to develop in up to $53 \%$ of patients with cirrhosis, ${ }^{7,8}$ comparable to prerenal azotemia and acute tubular necrosis, which have been reported to occur in up to $45 \%$ and $60 \%$ of patients with liver disease, respectively. ${ }^{7}$ HRS-AKI is characterized by rapid deterioration with little chance of spontaneous reversal of renal function; ${ }^{10,11}$ reversal can be possible if the condition is diagnosed and treated early, though the cirrhosis-induced renal dysfunction may not be reversible in many patients. ${ }^{2,7}$

\section{Pathophysiology}

The major pathological feature of HRS-AKI is extreme renal vasoconstriction secondary to portal hypertension (a characteristic of advanced cirrhosis) that leads to a severe reduction in glomerular filtration rate (GFR) ${ }^{8,12}$ The precise pathophysiology is not completely understood, ${ }^{13}$ but the predominant theory is that systemic hemodynamic changes in liver disease (eg, portal hypertension and stress) and/or bacterial translocation from the gut lead to vasodilator production and subsequent splanchnic vasodilation (Figure 1) ${ }^{7,8,14}$ Systemic vasodilation, reduced peripheral vascular resistance, and splanchnic arterial vasodilation may also be facilitated and lead to a reduction in the circulatory volume, triggering the renin-angiotensin-aldosterone system, sympathetic nervous system, and arginine vasopressin release to restore circulatory volume. ${ }^{7,8,14}$ This, in turn, can cause extreme renal vasoconstriction, diminished blood flow, and sodium and water retention leading to ascites and hyponatremia. ${ }^{8,14}$

Although circulatory dysfunction has been theorized to be the cause of HRS-AKI for many years, accumulating evidence suggests systemic inflammation may also be an

Table I The Current Diagnostic Criteria for HRS-AKI Compared with the Previous Definition for HRS-I

\begin{tabular}{|c|c|}
\hline HRS-AKI & HRS-I \\
\hline $\begin{array}{l}\text { - Diagnosis of cirrhosis and ascites } \\
\text { - Diagnosis of AKI according to ICA AKI diagnostic criteria } \\
\text { - No response at } 48 \text { hours of plasma volume expansion using } \\
\text { - albumin I g/kg of body weight and withdrawal of diuretics } \\
\text { - Absence of shock } \\
\text { - No current or recent use of nephrotoxic drugs } \\
\text { follows: } \\
\circ \text { Absence of proteinuria ( }<500 \mathrm{mg} / \mathrm{d}) \\
\circ \text { Absence of microhematuria }(<50 \mathrm{RBCs} \text { per high-power field) } \\
\circ \text { Normal renal ultrasonography }\end{array}$ & $\begin{array}{l}\text { - Diagnosis of cirrhosis and ascites } \\
\text { - Serum creatinine }>1.5 \mathrm{mg} / \mathrm{dL}(>133 \mathrm{mmol} / \mathrm{L}) \\
\text { - Noubling of serum creatinine over } 2.5 \mathrm{mg} / \mathrm{dL} \text { in }<2 \text { weeks } \\
\text { - diuretic withdrawal and expansion with albumin } \\
\text { - Absence of shock } \\
\text { - No current or recent use of nephrotoxic drugs } \\
\text { - Absence of parenchymal kidney disease, indicated by proteinuria }(>500 \mathrm{mg} / \\
\text { day), microhematuria ( }>50 \mathrm{RBCs} \text { per high-power field) and/or abnormal } \\
\text { renal ultrasonography }\end{array}$ \\
\hline
\end{tabular}

Note: Data from these studies $2,5,6,14,81$.

Abbreviations: AKI, acute kidney injury; HRS-I, hepatorenal syndrome type I; HRS-AKI, hepatorenal syndrome type of acute kidney injury; ICA, International Club of Ascites; RBCs, red blood cells. 


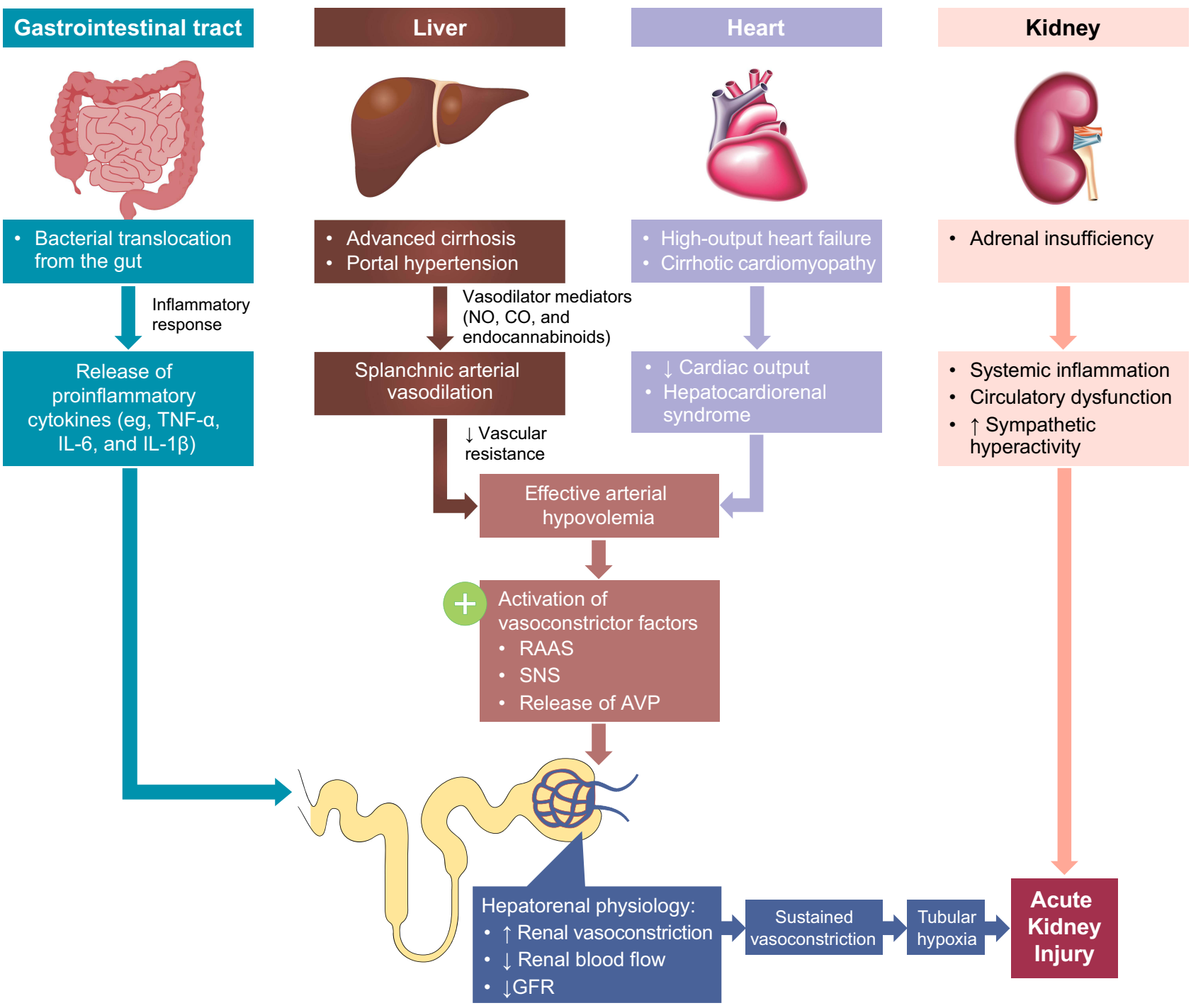

Figure I The multisystemic pathophysiology of HRS-AKI. Renal vasoconstriction is the key pathological mechanism associated with HRS-AKI. Patients with end-stage liver disease develop several multisystemic conditions that contribute to the development of AKI. Portal hypertension secondary to cirrhosis and subsequent vasodilator production leads to splanchnic arterial vasodilation. Additionally, high-output heart failure and cirrhotic cardiomyopathy lead to decreased cardiac output and hepatocardiorenal syndrome. The arterial vasodilation and decreased cardiac output together cause arterial hypovolemia and a reduction in circulatory volume, activating RAAS, SNS, and AVP release to restore circulatory volume. Alternately, in the gut, systemic inflammation secondary to bacterial translocation leads to the release of proinflammatory cytokines. The gastrointestinal and cardiac conditions combined cause increased renal vasoconstriction, decreased renal blood flow, and decreased GFR. This then leads to sustained vasoconstriction, tubular hypoxia, and AKI. Additionally, adrenal insufficiency can also lead to systemic inflammation, circulatory dysfunction, and sympathetic hyperactivity, further exacerbating acute kidney injury.

Abbreviations: AKI, acute kidney injury; AVP, arginine vasopressin; CO, carbon monoxide; GFR, glomerular filtration rate; HRS-AKI, hepatorenal syndrome type of acute kidney injury; IL; interleukin; NO, nitric oxide; RAAS, renin-angiotensin aldosterone system; SNS, sympathetic nervous system; TNF- $\alpha$, tumor necrosis factor alpha.

important contributor, likely arising from bacterial translocation and/or infection that trigger the release of proinflammatory cytokines, such as tumor necrosis factor-alpha, interleukin 6, and interleukin 1-beta. ${ }^{6,15,16}$ Additionally, recent histological and biomarker studies revealed signs of structural changes in patients with HRS-1, such as chronic or acute tubular interstitial injury, glomerular or vascular injury, and biomarkers suggesting parenchymal damage. ${ }^{17-19}$ Nonetheless, the precise mechanisms underlying HRS-AKI are yet to be determined.

\section{Diagnosis of HRS-AKI}

Currently, there is no gold standard test to diagnose HRSAKI and, thus, it is primarily completed by exclusion of differential diagnoses, and generally involves a clinical workup, abdominal imaging (eg, kidney and/or liver ultrasound), and laboratory assessments. ${ }^{5,7}$ Primary causes of renal failure (eg, hypovolemia, infection, or nephrotoxins) and other renal diseases need to be excluded before the diagnosis of HRS-AKI can be made. ${ }^{9}$ It is particularly important to distinguish HRS-AKI from HRS-NAKI, 
which is observed in patients with chronic kidney disease (CKD) or in those with acute kidney disease that does not meet the criteria for HRS-AKI. ${ }^{6}$ The International Club of Ascites has proposed several iterations of diagnostic criteria for HRS-1, and eventually HRS-AKI, which are provided in Table 1.5,14

The extreme renal vasoconstriction fundamental to HRS-AKI and subsequent reduction in GFR have informed the use of serum creatinine $(\mathrm{SCr})$ as a key laboratory marker to diagnose and monitor patients. ${ }^{5}$ Increasing knowledge about the disease process and concerns about the use of $\mathrm{SCr}$ as a marker in patients with cirrhosis have resulted in several updates to the $\mathrm{SCr}$ thresholds used for diagnosis. ${ }^{5,6,20}$ The most recent recommendations suggest that an absolute increase in $\mathrm{SCr}$ of $\geq 0.3 \mathrm{mg} / \mathrm{dL}$ within a 48 -hour period, or a $\geq 50 \%$ increase from the lowest $\mathrm{SCr}$ value observed over the prior 3 months, should be used in the diagnosis of HRS-AKI. These criteria are considered as an improvement over previous criteria for defining renal dysfunction in HRS-1 that required a doubling of $\mathrm{SCr}$ to $>2.5 \mathrm{mg} / \mathrm{dL}$ within 2 weeks. Greater sensitivity is afforded by removing the absolute value threshold in favor of dynamic changes that can be small $(0.3 \mathrm{mg} / \mathrm{dL})$ and over a longer period (3 months) to more rapidly identify and begin treating patients. The baseline period was extended to 3 months to prevent excessively high baseline values for patients who may initially present with advanced disease and allows the clinician to select an appropriate value over that time considering possible instability of repeated $\mathrm{SCr}$ measurements. ${ }^{6}$ Regardless of these advances, it is important to understand that $\mathrm{SCr}$ levels are affected by multiple external factors (eg, decreased formation of creatinine secondary to muscle wasting or increased volume of distribution), ${ }^{21}$ and to remain aware of the limitations when assessing the changes in its value. ${ }^{7}$

Another update to the newest diagnostic criteria was the addition of a decrease in urinary output to $\leq 0.5 \mathrm{~mL} / \mathrm{kg}$ body weight over 6 hours or more. However, there is a caveat that this should be limited to patients with a urinary catheter to ensure accurate measurements. ${ }^{6}$

Although not among the published diagnostic criteria for HRS-AKI, other laboratory markers may be more reliable than $\mathrm{SCr}$ to assess kidney function in patients with liver failure, such as inulin and iothalamate clearance to determine GFR, ${ }^{22,23}$ or direct assessment of creatinine clearance. ${ }^{20}$ However, these are not practical for everyday use owing to logistical and cost considerations and are urine-based tests that may be impractical in patients with low or no urine output. ${ }^{20}$

\section{Prognosis}

HRS-AKI is associated with reduced survival and an oftenpoor prognosis, contingent on the reversibility of kidney dysfunction and associated organ failures. ${ }^{3,8}$ Historic studies conducted in patients with HRS-1 revealed a median survival in the range of $1-4$ weeks, ${ }^{11,24}$ with more-recent findings reporting a median survival rate of only $8-12$ weeks, a low $25 \%$ survival rate after 30 days, and a 90 -day mortality rate of $57 \%$ for hospitalized patients. ${ }^{3,25}$ Mortality for patients with HRS-AKI is predicted through prognostic scores such as the Model for End-Stage Liver Disease (MELD), which uses $\mathrm{SCr}$ as a marker for renal function to determine liver transplant allocation. ${ }^{3}$ The presence of jaundice, hepatic encephalopathy, type of AKI, AKI stage at peak $\mathrm{SCr}$ value, SCr levels of $>1.5 \mathrm{mg} / \mathrm{dL}$, serum bilirubin level, serum glutamic oxaloacetic transaminase level, prothrombin time, International normalized ratio, Child-Turcotte-Pugh score, and MELD score have all been shown to be predictors of mortality in patients with cirrhosis and AKI. ${ }^{21}$

\section{Prevention and Treatments for HRS-AKI}

The goal of treatment for patients with HRS-AKI is permanent restoration of liver and kidney function. Yet, considering the severity and complexity of the disease, realistic treatment goals for most patients are more likely to be composed of intermediate steps to help prolong survival and avoid irreversible renal damage, such as improving systemic macrovascular dysfunction (eg, improving mean arterial pressure [MAP]) or improving markers of renal function (eg, increased GFR). ${ }^{7,26}$ In patients with liver disease who are at risk for HRS-AKI, prevention may be achievable and should be considered, if possible. Once a diagnosis is established, early treatment should focus on identifying and treating reversible factors such as dehydration, use of nephrotoxic medications, infections, and gastrointestinal bleeding. ${ }^{27}$ Long-term recommended treatment approaches include avoidance of triggers that can cause further renal damage, liver transplantation, pharmacotherapy, and renal replacement therapy. ${ }^{28}$

\section{Prevention}

In patients with cirrhosis and ascites who do not yet have HRS-AKI, medical management to prevent HRS-AKI is 
focused on avoidance of renal toxins and other factors that are known to increase the risk for AKI. This includes avoiding overuse of diuretics, avoiding nephrotoxic medications (such as nonsteroidal anti-inflammatory drugs, angiotensinconverting enzyme inhibitors and certain antibiotics [eg, fluoroquinolones, cephalosporins]), and preventing episodes of dehydration or hypovolemia. ${ }^{7,14}$ In addition, providers should monitor patients closely following large-volume paracentesis and provide appropriate doses of albumin for volume replacement. ${ }^{14}$ Infections should be identified early and treated promptly. ${ }^{14,29}$

For patients with cirrhosis and ascites with stage 1 AKI, plasma volume expansion by albumin administration may delay or prevent disease progression. The recommended therapy is albumin at $1 \mathrm{~g} / \mathrm{kg}$ of body weight per day (up to $100 \mathrm{~g}$ per day), administered for 2 days and then reevaluated. ${ }^{5}$ Albumin administration is intended to help maintain or restore vascular tone to counteract macrovascular dysfunction associated with disease progression. $^{30}$ However, albumin has other beneficial functions such as antioxidant activity, detoxification, maintenance of endothelial integrity, and anti-inflammatory properties. $^{31}$ In addition to preventing HRS, albumin administration has been associated with improved survival in patients with cirrhosis and spontaneous bacterial peritonitis. $^{32,33}$ Note that no response to albumin after 2 days is a suggested criterion for diagnosis of HRS-AKI, ${ }^{6}$ and if confirmed, albumin administration usually continues in combination with vasoconstrictor agents.

Pentoxifylline is a nonselective phosphodiesterase inhibitor that can reduce inflammation and induce vasoconstriction. ${ }^{34}$ In clinical trials, pentoxifylline prevented HRS in some patients with cirrhosis, ascites, and creatinine clearance of up to $80 \mathrm{~mL} / \mathrm{min}$ and has shown mixed results in studies assessing potential survival benefits in patients with severe alcoholic hepatitis. $^{35-38}$ However, further investigation of treatment with pentoxifylline in the setting of HRS-AKI is needed. ${ }^{14}$

Other steps to help prevent HRS-AKI include administration of prophylactic antibiotics to prevent bacterial infection, maintenance of proper fluid balance, and general supportive measures such as vital signs monitoring, standard liver and renal tests, and ongoing clinical assessment. $^{1,8}$ Some patients with ascites may benefit from paracentesis (especially for tense ascites), and/or elimination of diuretics, maintaining electrolyte balance, and promptly treating infections. 1,28

\section{Transplantation}

The most effective intervention and only potential cure for HRS-AKI is liver transplantation. ${ }^{7,28}$ Data suggest this approach induces HRS reversal in up to $70 \%$ of patients with HRS-AKI, ${ }^{39}$ but $\geq 30 \%$ of patients do not achieve full kidney recovery after transplant. The probability of HRS reversal after transplant may be reduced in patients who are older, have alcoholic cirrhosis, or receive an ineffective donor liver. ${ }^{40}$ Furthermore, not all patients with HRS-AKI are appropriate transplantation candidates, and donor organs are in very limited supply. ${ }^{41}$ Allocations for liver transplants are based on SCr levels factored into prognostic measures such as the MELD score and the Chronic Liver Failure-Sequential Organ Failure Assessment (CLIF-SOFA). ${ }^{3}$

\section{Pharmacotherapy}

The use of vasoconstrictive drug therapy is the primary pharmacologic approach for the treatment of patients with HRS-AKI. ${ }^{28}$ Treatment with systemic vasoconstrictors has been shown to improve renal blood flow, likely through increasing effective intravascular volume and MAP, particularly in the splanchnic vasculature, and reducing reninangiotensin-aldosterone and sympathetic nervous system activity. $^{42,43}$ Vasoconstrictor therapy coadministered with albumin ( $1 \mathrm{~g} / \mathrm{kg}$ per day) has been associated with reduced mortality compared with no treatment or albumin alone in patients with HRS. ${ }^{6}$

Terlipressin, a synthetic analog of vasopressin that activates vasopressin receptors to cause systemic vasoconstriction, is considered a first-line therapeutic option in countries where it is available. ${ }^{28}$ Clinical data suggest that terlipressin plus albumin can restore renal function in up to $24-35 \%$ of patients and may improve transplant-free survival; ${ }^{44-48}$ some, but not all, data reported to date suggest treatment with terlipressin may be associated with reduced mortality. $^{44,46,47}$ Coadministration of albumin is recommended for patients receiving terlipressin until total or partial response, or for up to 2 weeks. ${ }^{6}$ Terlipressin is not currently available in North America, but a large Phase 3, placebo-controlled study in North American patients with HRS-1 has been recently completed. Currently, the combination of midodrine (an alpha-1 adrenergic agonist that acts as a vasoconstrictor) plus octreotide (a somatostatin analog) is the most commonly used treatment for HRS-AKI in the United States. ${ }^{7,28}$ However, treatment with midodrine plus octreotide has shown marginal efficacy, and there are no 
data from large-scale prospective controlled studies to support its use. ${ }^{7}$ Treatment with midodrine plus octreotide has been shown to be less effective than terlipressin for the treatment of HRS-AKI. ${ }^{49}$

Norepinephrine by continuous infusion can increase arterial pressure, reverse renal impairment, and improve short-term survival. ${ }^{50,51}$ In a recent trial, patients who responded to norepinephrine also showed a significant decrease in $\mathrm{SCr}$ and significant increases in creatinine clearance and urine output. ${ }^{52}$ Availability and cost may drive norepinephrine use in some countries; however, use of norepinephrine may be limited by adverse effects and the need for central venous administration in an intensive care setting. ${ }^{28}$ Results from most of the comparative studies of norepinephrine versus terlipressin conducted to date have shown similar efficacy in patients with HRS-AKI. ${ }^{50,53-57}$

\section{Transjugular Intrahepatic Portosystemic Shunt}

Transjugular intrahepatic portosystemic shunt placement decompresses the portal system, enhances peripheral arterial vasodilation in the short-term post-insertion, and can improve circulatory hemodynamics, renal function, and sodium homeostasis within several weeks after insertion. $^{28,58,59} \mathrm{~A}$ recent meta-analysis determined that transjugular intrahepatic portosystemic shunt placement in patients with HRS-AKI had improved SCr levels, urine volume, and urinary sodium excretion; however, data are limited overall, and transjugular intrahepatic portosystemic shunt may not be feasible in patients with severe liver failure or severe hepatic encephalopathy. ${ }^{28,59}$

\section{Renal Replacement Therapy}

Renal replacement therapy (RRT), including intermittent hemodialysis and continuous veno-venous hemodialysis, ${ }^{60}$ is often required for renal failure in patients with AKI or $\mathrm{CKD}$ and is used as a bridge for patients scheduled to receive a liver transplant; ${ }^{27}$ sometimes, however, it is used for patients who are ineligible for a liver transplant and who have end-stage renal disease or do not respond to vasoconstrictors. $^{28}$ The indications for RRT in patients with HRS-AKI are the same as that for any other cause of AKI, ${ }^{27}$ but routine use of RRT in patients with HRSAKI is somewhat controversial because of the risk for the development of hemodynamic instability, coagulopathy, and thrombocytopenia; RRT may not provide incremental benefit in survival for those treated with vasoconstrictors and albumin. ${ }^{61}$ Also, the preferred mode of dialysis for patients with HRS-AKI remains unknown. ${ }^{27}$ No evidence exists to suggest RRT increases long-term survival without liver transplantation. ${ }^{14,62}$ Some patients with advanced renal disease may require dialysis, or need a kidney transplant, which can be performed during a liver transplant if clinically indicated, or at a later date if the patient does not recover kidney function after the liver transplant. ${ }^{28,63}$ Potentially serious treatment-related adverse events of RRT may be life-threatening in some patients and include: vascular-access failure or infection in patients using hemodialysis $(9.3 \%$ of all deaths); RRT complications in patients using hemodialysis or peritoneal dialysis (5.8\% of all deaths); peritoneal infection in patients using peritoneal dialysis (3.1\% of all deaths); noncompliance in patients using any modality ( $4.0 \%$ of all deaths); and healthcare-associated infection in patients using any modality $(9.6 \%$ of all deaths $) .{ }^{64}$

\section{Associated and/or Causative Conditions}

Several other factors may contribute to or exacerbate vascular changes likely fundamental to HRS-AKI.

Cardiomyopathy is common in patients with cirrhosis and can reduce cardiac output and contribute to hypovolemia and kidney dysfunction. ${ }^{14,65}$ Autonomic dysfunction and reduced baroreflex sensitivity are also observed in patients with advanced cirrhosis, which can also contribute to reduced cardiac output and altered hemodynamics. ${ }^{30,66}$

Adrenal insufficiency affects up to $65 \%$ of patients with decompensated cirrhosis and ascites ${ }^{7}$ and is associated with systemic inflammation, circulatory dysfunction, and increased sympathetic hyperactivity. ${ }^{67,68}$ Patients with this condition can experience impairment of circulatory function and reduced systemic blood pressure, which increases the risk of HRS-AKI and mortality. ${ }^{7,67}$

Ascites can lead to a range of complications such as intra-abdominal hypertension, abdominal compartment syndrome, increased renal vein pressure, and worsening kidney function. ${ }^{69}$ Large-volume paracentesis can lead to paracentesis-induced circulatory dysfunction, which involves increased renin activity and potentially contributes to systemic vascular dysfunction. ${ }^{7}$ Treatment with intravenous albumin may reduce the risk of HRS in patients with paracentesis-induced circulatory dysfunction. ${ }^{70,71}$ Spontaneous bacterial peritonitis (SBP) is common in patients with ascites and is 
also considered a major precipitating factor for the onset of HRS-AKI. For some patients with advanced cirrhosis, HRS-AKI may be preventable with primary antibiotic prophylaxis. ${ }^{72}$ Treatment with albumin may also reduce the risk of HRS development and mortality in patients with ascites and SBP, ${ }^{32,73}$ but some studies do not support the use of albumin to reduce the risk of HRS in patients with sepsis. ${ }^{74,75}$

As mentioned above, certain drugs may also contribute to HRS-AKI onset. Excessive use of diuretics or nonsteroidal anti-inflammatory drugs may cause renal failure in patients with cirrhosis and use of nonselective beta-blocking agents, sometimes used for prophylaxis of variceal bleeding in patients with cirrhosis, is controversial and may increase the risk of HRS and mortality in some patients. ${ }^{28,76,77}$ Current guidelines recommend that all of the above treatments be discontinued or reduced in patients with cirrhosis who are at risk for HRS-AKI. ${ }^{6,28,76,78,79}$

Malnutrition is also common, affecting more than $50 \%$ of patients with decompensated liver disease. ${ }^{80}$ This can lead to loss of muscle tissue and fat deposits, and is associated with complications such as refractory ascites, SBP, HRS, and reduced survival. ${ }^{58,78,80}$ Current nutritional guidelines recommend that nonobese patients with chronic liver disease consume at least $35 \mathrm{kcal} / \mathrm{kg} /$ day (based on "dry weight" if ascites is present) and receive macro- and micronutrient supplementation as needed. ${ }^{80}$ Sodium restriction and diuretic use are common in the management of ascites; ${ }^{28}$ yet, sodium restrictions must balance the potential for reduced palatability as even moderate sodium restriction is associated with reduced caloric intake and nutritional status. ${ }^{28,80}$ Therefore, guidelines suggest that dietary sodium restrictions remain between 1840 and $2760 \mathrm{mg} /$ day, and not below $1380 \mathrm{mg} /$ day. $^{28,80}$

\section{Management}

HRS-AKI is associated not only with a negative impact on patient survival and outcomes, but also with poor quality of life and high socio-economic burdens due to the healthcare costs associated with necessary treatments. ${ }^{27}$

\section{Patient Counseling in HRS-AKI}

Because of the severe and multifactorial nature of HRS-AKI, clinicians, patients, and caregivers face a variety of issues related to the disease and its treatment. These include conditions that may contribute to or arise from HRS-AKI, and/or could influence eligibility for, or effectiveness of, certain treatments. Patients and their caregivers need very specific guidance and education to remain actively engaged and acquire the knowledge needed to make informed decisions. Table 2 provides a summary of the common issues that patients and care teams coping with HRS-AKI take into consideration, as well as some of the actions and responsibilities that can help improve outcomes and patient comfort. These cover medical issues in addition to broader themes regarding optimizing the patient experience. Overall, patients and care providers must remain vigilant, active, engaged, and flexible given the severity of HRS-AKI and the number and unpredictability of possible disease-related conditions. Effective counselling can help patients adhere to their care plan, which will likely include medications, dietary restrictions, persistent monitoring of signs and symptoms, and treatment from multiple providers. Potential barriers include gaps in insurance coverage, need for primary caregivers to maintain full-time employment to keep health-care benefits, lack of availability of a secondary caregiver, financial concerns, and possible need for relocation to a medical center with a transplant center (often difficult for patients who live in remote, rural areas of the country).

\section{Posttransplant Management in HRS-AKI}

End-stage renal disease and CKD can develop in the postliver transplant period and, thus, patients should be monitored closely for risk factors. ${ }^{27}$ The risk factors for end-stage renal disease include calcineurin inhibitor nephrotoxicity, pre-existing HRS or renal insufficiency, and diabetes mellitus. ${ }^{27}$ Risk factors for CKD include episodes of acute renal failure, the use of RRT pretransplant and posttransplant, hepatitis $\mathrm{C}$ infection, and increasing age. ${ }^{27}$

\section{Palliative Care in Patients Ineligible for Liver Transplant}

Patients with HRS-AKI who are ineligible for a liver transplant have a high short-term mortality rate. ${ }^{27}$ In clinical settings, these patients are rarely offered palliativecare consultations but generally experience poor quality of life, prolonged hospitalizations, and high financial burden. ${ }^{27}$ Consultations should be provided on a case-bycase basis when discussing long-term care options for these patients and their families. ${ }^{27}$

\section{Financial Burden Associated with HRS-AKI}

HRS is the leading cause of hospitalization for patients with chronic liver disease. ${ }^{25}$ As a disease in which 
Table 2 Key Issues Requiring Patient Counselling in HRS-AKI

\begin{tabular}{|c|c|c|}
\hline Issue & Treatment Options and Role(s) of Clinical Staff & Role of Patient and/or Caregiver \\
\hline $\begin{array}{l}\text { Ascites and/or fluid } \\
\text { retention }\end{array}$ & $\begin{array}{l}\text { - Advise dietary modifications, eg, sodium reduction to }<2 \mathrm{~g} / 24 \mathrm{~h} \\
\text { - Withhold diuretics } \\
\text { - Therapeutic paracentesis to control volume/avoid tense ascites } \\
\text { - Antibiotic prophylaxis to avoid infections, especially for low-protein } \\
\text { ascites fluid or history of prior SBP }\end{array}$ & $\begin{array}{l}\text { - Check body weight daily; contact pro- } \\
\text { vider for rapid weight gain (eg, }>5 \mathrm{lb} \text { in } \\
2 \text { days) }\end{array}$ \\
\hline Hepatic encephalopathy & $\begin{array}{l}\text { - Treat triggering event (eg, infection, Gl bleeding, kidney dysfunction) } \\
\text { - Prevent recurrence by reducing toxins; treat with lactulose and/or } \\
\text { rifaximin }\end{array}$ & $\begin{array}{l}\text { - Avoid dehydration } \\
\text { - Monitor for changes in personality/ } \\
\text { behavior } \\
\text { - Treatment adherence }\end{array}$ \\
\hline $\begin{array}{l}\text { Esophageal varices } / \mathrm{Gl} \\
\text { bleeding treated with beta } \\
\text { blockers }\end{array}$ & - Eliminate beta blockers, if feasible & - Monitor for symptoms of recurrence \\
\hline Diabetes & $\begin{array}{l}\text { - Terminate oral hypoglycemic treatment and begin an insulin regimen } \\
\text { - Advise dietary changes to optimize blood sugar control (diabetic } \\
\text { diet) }\end{array}$ & - Dietary adherence, sugar control \\
\hline Malnutrition and/or debility & $\begin{array}{l}\text { - Advise a high-protein diet } \\
\text { - Considerations for other dietary changes, such as diabetic diet, low } \\
\text { sodium/fluid restriction (if ascites and/or hyponatremia), renal diet } \\
\text { - Nutrition consultation plus physical or occupational therapy to } \\
\text { increase strength and reduce sarcopenia/malnutrition }\end{array}$ & $\begin{array}{l}\text { - Attend nutritional consultation and } \\
\text { regular follow-ups }\end{array}$ \\
\hline Hyponatremia & $\begin{array}{l}\text { - Monitor for hyponatremia } \\
\text { - Monitor for decline in kidney function/end-stage renal disease; initiate } \\
\text { RRT } \\
\text { - Advise dietary changes, ie, fluid restriction or renal diet if applicable }\end{array}$ & $\begin{array}{l}\text { - Attend nutritional consultation if advised } \\
\text { - Dietary adherence; fluid restriction } \\
\text { - Monitor urination; report reduced } \\
\text { frequency }\end{array}$ \\
\hline Hypotension & $\begin{array}{l}\text { - Ongoing vigilance } \\
\text { - Modify treatment regimen as needed (ie, initiate midodrine in } \\
\text { improve renal blood flow and pressure) }\end{array}$ & $\begin{array}{l}\text { - Rigorous tracking of blood pressure and } \\
\text { heart rate } \\
\text { - Medication adherence } \\
\text { - Prompt reporting of changes to clinical } \\
\text { team }\end{array}$ \\
\hline Polypharmacy & $\begin{array}{l}\text { - Monitor prescriptions/treatments } \\
\text { - Vigilance for potential drug-drug or drug-food interactions }\end{array}$ & $\begin{array}{l}\text { - Medication adherence } \\
\text { - Reporting of side effects }\end{array}$ \\
\hline Overall patient care & $\begin{array}{l}\text { - Nurse navigator/coordinator to advise patient and/or clinical team } \\
\text { regarding changes in health status or treatments, especially starting/ } \\
\text { stopping medications } \\
\text { - Patient/caregiver education on ways to prevent renal injury (ie, } \\
\text { avoidance of certain medications, monitoring of weight fluctuations, } \\
\text { noting if increase or decrease in urine output, minimize risk for } \\
\text { dehydration or risk for infections) }\end{array}$ & $\begin{array}{l}\text { - Engagement with treatment team } \\
\text { - Adherence to treatment regimen(s) }\end{array}$ \\
\hline
\end{tabular}

Abbreviations: GI, gastrointestinal; HRS-AKI, hepatorenal syndrome type of acute kidney injury; RRT, renal replacement therapy; SBP, spontaneous bacterial peritonitis.

diagnosis is determined only by exclusion of other factors, often several procedures and medications are used before the diagnosis of HRS is reached, further increasing the overall cost of treatment. ${ }^{25}$ Significant cost drivers in this patient population include mortality, length of hospital stay, and administration of RRT, with an average total 
charge of \$80,000-\$90,000 per patient. Regardless of this high cost, however, only about $45 \%$ of patients with HRS experience an improvement in SCr levels of $<20 \%$, suggesting a need for cost-effective and efficacious treatments for HRS. ${ }^{25}$

\section{Conclusions}

HRS-AKI is a severe, multi-organ disorder with a complex etiology. This condition is the culmination of liver failure that has progressed to the point of inducing kidney failure as well, leaving patients in very poor health with limited treatment options. Liver transplant is the only curative treatment, but not all patients are appropriate candidates for liver transplant, and nearly one-third of patients who do successfully undergo the procedure fail to show improvement in renal function. Therefore, other therapeutic interventions are used. During the past decade, recommended criteria for defining renal dysfunction in HRS-AKI have evolved away from the use of a static threshold (doubling of SCr to $\geq 2.5 \mathrm{mg} / \mathrm{dL}$ within 2 weeks) to use of a more dynamic definition (increase in $\mathrm{SCr}$ of $\geq 0.3 \mathrm{mg} / \mathrm{dL}$ over a 48 hour period or $\mathrm{a} \geq 50 \%$ increase over a 3 -month period). These changes facilitate earlier diagnosis and treatment of this condition and are likely to increase potential for improved patient outcomes. Vasoconstrictor-based treatment has been shown to improve renal function in these patients and can help support survival until a liver transplant is possible in patients awaiting a transplant. The complexity of this disease poses many challenges for patient care and presents opportunities for family and patient counselling to help maintain or improve patient health status while coping with this severe and debilitating condition.

\section{Data Sharing Statement}

Data sharing is not applicable as no data sets were generated and/or analyzed for this review.

\section{Acknowledgments}

Medical writing and editorial support were provided in accordance with Good Publication Practice (GPP3) and the guidelines of the International Committee of Medical Journal Editors (ICMJE) by Michael D. Morren, RPh, MBA, of Peloton Advantage, LLC, an OPEN Health company, Parsippany, NJ; and further editorial services were provided by Oxford PharmaGenesis Inc., Newtown, PA; all funded by Mallinckrodt Pharmaceuticals.

\section{Author Contributions}

The author made a significant contribution to the work reported in the conception and design, acquisition of materials, analysis and interpretation of the work, reviewed each draft of the article, gave final approval of the version to be published, agreed to the submitted journal, and agrees to be accountable for all aspects of the work.

\section{Funding}

This review was funded by Mallinckrodt Pharmaceuticals.

\section{Disclosure}

The author reports no conflicts of interest in this work.

\section{References}

1. European Association for the Study of the Liver. EASL clinical practice guidelines on the management of ascites, spontaneous bacterial peritonitis, and hepatorenal syndrome in cirrhosis. $J$ Hepatol. 2010;53(3):397-417. doi:10.1016/j.jhep.2010.05.004

2. Salerno F, Gerbes A, Gines P, Wong F, Arroyo V. Diagnosis, prevention and treatment of hepatorenal syndrome in cirrhosis. Gut. 2007;56 (9):1310-1318.

3. Allegretti AS, Ortiz G, Wenger J, et al. Prognosis of acute kidney injury and hepatorenal syndrome in patients with cirrhosis: a prospective cohort study. Int J Nephrol. 2015;2015:108139. doi:10.1155/2015/108139

4. Arroyo V, Gines P, Gerbes AL, et al. Definition and diagnostic criteria of refractory ascites and hepatorenal syndrome in cirrhosis. Hepatology. 1996;23(1):164-176. doi:10.1002/hep.510230122

5. Angeli P, Gines P, Wong F, et al. Diagnosis and management of acute kidney injury in patients with cirrhosis: revised consensus recommendations of the International Club of Ascites. J Hepatol. 2015;62 (4):968-974. doi:10.1016/j.jhep.2014.12.029

6. Angeli P, Garcia-Tsao G, Nadim MK, Parikh CR. News in pathophysiology, definition and classification of hepatorenal syndrome: a step beyond the International Club of Ascites (ICA) consensus document. J Hepatol. 2019;71(4):811-822. doi:10.1016/j.jhep.2019.07.002

7. Velez JCQ, Therapondos G, Juncos LA. Reappraising the spectrum of AKI and hepatorenal syndrome in patients with cirrhosis. Nat Rev Nephrol. 2020;16(3):137-155. doi:10.1038/s41581-019-0218-4

8. Gines P, Sola E, Angeli P, Wong F, Nadim MK, Kamath PS. Hepatorenal syndrome. Nat Rev Dis Primers. 2018;4(1):23. doi:10.1038/s41572-018-0022-7

9. Lenz K, Buder R, Kapun L, Voglmayr M. Treatment and management of ascites and hepatorenal syndrome: an update. Therap $A d v$ Gastroenterol. 2015;8(2):83-100. doi:10.1177/1756283X14564673

10. Gines P, Guevara M, Arroyo V, Rodes J. Hepatorenal syndrome. Lancet. 2003;362(9398):1819-1827. doi:10.1016/S0140-6736(03) 14903-3

11. Alessandria C, Ozdogan O, Guevara M, et al. MELD score and clinical type predict prognosis in hepatorenal syndrome: relevance to liver transplantation. Hepatology. 2005;41(6):1282-1289. doi:10.1002/hep.20687

12. Gines P, Schrier RW. Renal failure in cirrhosis. $N$ Engl $J$ Med. 2009;361(13):1279-1290. doi:10.1056/NEJMra0809139 
13. Colle I, Laterre PF. Hepatorenal syndrome: the clinical impact of vasoactive therapy. Expert Rev Gastroenterol Hepatol. 2018;12 (2):173-188. doi:10.1080/17474124.2018.1417034

14. Amin AA, Alabsawy EI, Jalan R, Davenport A. Epidemiology, pathophysiology, and management of hepatorenal syndrome. Semin Nephrol. 2019;39(1):17-30. doi:10.1016/j. semnephrol.2018.10.002

15. Navasa M, Follo A, Filella X, et al. Tumor necrosis factor and interleukin-6 in spontaneous bacterial peritonitis in cirrhosis: relationship with the development of renal impairment and mortality. Hepatology. 1998;27(5):1227-1232. doi:10.1002/ hep. 510270507

16. Trebicka J, Amoros A, Pitarch C, et al. Addressing profiles of systemic inflammation across the different clinical phenotypes of acutely decompensated cirrhosis. Front Immunol. 2019;10:476. doi:10.3389/fimmu.2019.00476

17. Trawale JM, Paradis V, Rautou PE, et al. The spectrum of renal lesions in patients with cirrhosis: a clinicopathological study. Liver Int. 2010;30(5):725-732. doi:10.1111/j.1478-3231.2009.02182.x

18. Ariza X, Sola E, Elia C, et al. Analysis of a urinary biomarker panel for clinical outcomes assessment in cirrhosis. PLoS One. 2015;10(6): e0128145. doi:10.1371/journal.pone.0128145

19. Belcher JM, Sanyal AJ, Peixoto AJ, et al. Kidney biomarkers and differential diagnosis of patients with cirrhosis and acute kidney injury. Hepatology. 2014;60(2):622-632. doi:10.1002/hep.26980

20. Mindikoglu AL, Pappas SC. New developments in hepatorenal syndrome. Clin Gastroenterol Hepatol. 2018;16(2):162-177.e1. doi:10.1016/j.cgh.2017.05.041

21. Kumar U, Kumar R, Jha SK, Jha AK, Dayal VM, Kumar A. Shortterm mortality in patients with cirrhosis of the liver and acute kidney injury: a prospective observational study. Indian J Gastroenterol. 2020;39(5):457-464. doi:10.1007/s12664-020-01086-Z

22. Stevens LA, Levey AS. Measured GFR as a confirmatory test for estimated GFR. J Am Soc Nephrol. 2009;20(11):2305-2313. doi:10.1681/ASN.2009020171

23. Gerbes AL, Gulberg V, Bilzer M, Vogeser M. Evaluation of serum cystatin $\mathrm{C}$ concentration as a marker of renal function in patients with cirrhosis of the liver. Gut. 2002;50(1):106-110. doi:10.1136/gut.50.1.106

24. Gines A, Escorsell A, Gines P, et al. Incidence, predictive factors, and prognosis of the hepatorenal syndrome in cirrhosis with ascites. Gastroenterology. 1993;105(1):229-236. doi:10.1016/0016-5085(93) 90031-7

25. Jamil K, Huang X, Lovelace B, Pham AT, Lodaya K, Wan G. The burden of illness of hepatorenal syndrome (HRS) in the United States: a retrospective analysis of electronic health records. $J$ Med Econ. 2019;22(5):421-429. doi:10.1080/13696998.2019.1580201

26. Wadei HM, Mai ML, Ahsan N, Gonwa TA. Hepatorenal syndrome: pathophysiology and management. Clin J Am Soc Nephrol. 2006;1 (5):1066-1079. doi:10.2215/CJN.01340406

27. Tariq R, Singal AK. Management of hepatorenal syndrome: a review. $J$ Clin Transl Hepatol. 2020;8(2):192-199. doi:10.14218/ JCTH.2020.00011

28. European Association for the Study of the Liver. EASL Clinical Practice Guidelines for the management of patients with decompensated cirrhosis. J Hepatol. 2018;69(2):406-460.

29. Modi RM, Patel N, Metwally SN, Mumtaz K. Outcomes of liver transplantation in patients with hepatorenal syndrome. World J Hepatol. 2016;8(24):999-1011. doi:10.4254/wjh.v8.i24.999

30. Moller S, Iversen JS, Henriksen JH, Bendtsen F. Reduced baroreflex sensitivity in alcoholic cirrhosis: relations to hemodynamics and humoral systems. Am J Physiol Heart Circ Physiol. 2007;292(6): H2966-H2972. doi:10.1152/ajpheart.01227.2006

31. Tufoni M, Zaccherini G, Caraceni P, Bernardi M. Albumin: indications in chronic liver disease. United European Gastroenterol J. 2020;8(5):528-535. doi:10.1177/2050640620910339
32. Sort P, Navasa M, Arroyo V, et al. Effect of intravenous albumin on renal impairment and mortality in patients with cirrhosis and spontaneous bacterial peritonitis. $N$ Engl J Med. 1999;341(6):403-409. doi:10.1056/NEJM199908053410603

33. Afinogenova Y, Tapper EB. The efficacy and safety profile of albumin administration for patients with cirrhosis at high risk of hepatorenal syndrome is dose dependent. Gastroenterol Rep. 2015;3 (3):216-221. doi:10.1093/gastro/gov032

34. Stine JG, Wang J, Cornella SL, et al. Treatment of type-1 hepatorenal syndrome with pentoxifylline: a randomized placebo controlled clinical trial. Ann Hepatol. 2018;17(2):300-306. doi:10.5604/ 01.3001 .0010 .8661

35. Tyagi P, Sharma P, Sharma BC, Puri AS, Kumar A, Sarin SK. Prevention of hepatorenal syndrome in patients with cirrhosis and ascites: a pilot randomized control trial between pentoxifylline and placebo. Eur $J$ Gastroenterol Hepatol. 2011;23(3):210-217. doi:10.1097/MEG.0b013e3283435d76

36. Akriviadis E, Botla R, Briggs W, Han S, Reynolds T, Shakil O. Pentoxifylline improves short-term survival in severe acute alcoholic hepatitis: a double-blind, placebo-controlled trial. Gastroenterology. 2000;119(6):1637-1648. doi:10.1053/gast.2000.20189

37. Parker R, Armstrong MJ, Corbett C, Rowe IA, Houlihan DD. Systematic review: pentoxifylline for the treatment of severe alcoholic hepatitis. Aliment Pharmacol Ther. 2013;37(9):845-854. doi:10.1111/apt.12279

38. Thursz MR, Richardson P, Allison M, et al. Prednisolone or pentoxifylline for alcoholic hepatitis. $N$ Engl $J$ Med. 2015;372 (17):1619-1628. doi:10.1056/NEJMoa1412278

39. Utako P, Emyoo T, Anothaisintawee T, Yamashiki N, Thakkinstian A, Sobhonslidsuk A. Clinical outcomes after liver transplantation for hepatorenal syndrome: a systematic review and meta-analysis. Biomed Res Int. 2018;2018:5362810. doi:10.1155/2018/5362810

40. Marik PE, Wood K, Starzl TE. The course of type 1 hepato-renal syndrome post liver transplantation. Nephrol Dial Transplant. 2006;21(2):478-482. doi:10.1093/ndt/gfi212

41. Merion RM, Schaubel DE, Dykstra DM, Freeman RB, Port FK, Wolfe RA. The survival benefit of liver transplantation. Am J Transplant. 2005;5 (2):307-313. doi:10.1111/j.1600-6143.2004.00703.x

42. Zhou X, Tripathi D, Song T, et al. Terlipressin for the treatment of acute variceal bleeding: a systematic review and meta-analysis of randomized controlled trials. Medicine. 2018;97(48):e13437. doi:10.1097/MD.0000000000013437

43. Jamil K, Pappas SC, Devarakonda KR. In vitro binding and receptor-mediated activity of terlipressin at vasopressin receptors $\mathrm{V}_{1}$ and $\mathrm{V}_{2}$. J Exp Pharmacol. 2018;10:1-7. doi:10.2147/JEP.S146034

44. Sanyal AJ, Boyer T, Garcia-Tsao G, et al. A randomized, prospective, double-blind, placebo-controlled trial of terlipressin for type 1 hepatorenal syndrome. Gastroenterology. 2008;134(5):1360-1368. doi:10.1053/j.gastro.2008.02.014

45. Martin-Llahi M, Pepin MN, Guevara M, et al. Terlipressin and albumin vs albumin in patients with cirrhosis and hepatorenal syndrome: a randomized study. Gastroenterology. 2008;134 (5):1352-1359. doi:10.1053/j.gastro.2008.02.024

46. Boyer TD, Sanyal AJ, Wong F, et al. Terlipressin plus albumin is more effective than albumin alone in improving renal function in patients with cirrhosis and hepatorenal syndrome type 1 . Gastroenterology. 2016;150(7):1579-1589. doi:10.1053/j. gastro.2016.02.026

47. Gluud LL, Christensen K, Christensen E, Krag A. Systematic review of randomized trials on vasoconstrictor drugs for hepatorenal syndrome. Hepatology. 2010;51(2):576-584. doi:10.1002/hep.23286

48. Restuccia T, Ortega R, Guevara M, et al. Effects of treatment of hepatorenal syndrome before transplantation on posttransplantation outcome. A case-control study. J Hepatol. 2004;40(1):140-146. doi:10.1016/j.jhep.2003.09.019 
49. Cavallin M, Kamath PS, Merli M, et al. Terlipressin plus albumin versus midodrine and octreotide plus albumin in the treatment of hepatorenal syndrome: a randomized trial. Hepatology. 2015;62 (2):567-574. doi:10.1002/hep.27709

50. Alessandria C, Ottobrelli A, Debernardi-Venon W, et al. Noradrenalin vs terlipressin in patients with hepatorenal syndrome: a prospective, randomized, unblinded, pilot study. J Hepatol. 2007;47(4):499-505. doi:10.1016/j.jhep.2007.04.010

51. Duvoux C, Zanditenas D, Hezode C, et al. Effects of noradrenalin and albumin in patients with type I hepatorenal syndrome: a pilot study. Hepatology. 2002;36(2):374-380. doi:10.1053/ jhep.2002.34343

52. Gupta K, Rani P, Rohatgi A, et al. Noradrenaline for reverting hepatorenal syndrome: a prospective, observational, single-center study. Clin Exp Gastroenterol. 2018;11:317-324. doi:10.2147/CEG. $\mathrm{S} 153858$

53. Goyal O, Sidhu SS, Sehgal N, Puri S. Noradrenaline is as effective as terlipressin in hepatorenal syndrome type 1: a prospective, randomized trial. J Assoc Physicians India. 2016;64(9):30-35.

54. Saif RU, Dar HA, Sofi SM, Andrabi MS, Javid G, Zargar SA. Noradrenaline versus terlipressin in the management of type 1 hepatorenal syndrome: a randomized controlled study. Indian J Gastroenterol. 2018;37(5):424-429. doi:10.1007/s12664-018-0876-3

55. Sharma P, Kumar A, Shrama BC, Sarin SK. An open label, pilot, randomized controlled trial of noradrenaline versus terlipressin in the treatment of type 1 hepatorenal syndrome and predictors of response. Am J Gastroenterol. 2008;103(7):1689-1697. doi:10.1111/j.15720241.2008.01828.x

56. Singh V, Ghosh S, Singh B, et al. Noradrenaline vs. terlipressin in the treatment of hepatorenal syndrome: a randomized study. J Hepatol. 2012;56(6):1293-1298. doi:10.1016/j.jhep.2012.01.012

57. Arora V, Maiwall R, Rajan V, et al. Terlipressin is superior to noradrenaline in the management of acute kidney injury in acute on chronic liver failure. Hepatology. 2020;71(2):600-610. doi:10.1002/ hep. 30208

58. Rossle M, Gerbes AL. TIPS for the treatment of refractory ascites, hepatorenal syndrome and hepatic hydrothorax: a critical update. Gut. 2010;59(7):988-1000. doi:10.1136/gut.2009.193227

59. Song T, Rossle M, He F, Liu F, Guo X, Qi X. Transjugular intrahepatic portosystemic shunt for hepatorenal syndrome: a systematic review and meta-analysis. Dig Liver Dis. 2018;50(4):323-330. doi:10.1016/j.dld.2018.01.123

60. Sourianarayanane A, Raina R, Garg G, McCullough AJ, O'Shea RS. Management and outcome in hepatorenal syndrome: need for renal replacement therapy in non-transplanted patients. Int Urol Nephrol. 2014;46(4):793-800. doi:10.1007/s11255-013-0527-7

61. Zhang Z, Maddukuri G, Jaipaul N, Cai CX. Role of renal replacement therapy in patients with type 1 hepatorenal syndrome receiving combination treatment of vasoconstrictor plus albumin. J Crit Care. 2015;30(5):969-974. doi:10.1016/j.jcrc.2015.05.006

62. Ahmed AR, Obilana A, Lappin D. Renal replacement therapy in the critical care setting. Crit Care Res Pract. 2019;2019:6948710.

63. Eason JD, Gonwa TA, Davis CL, Sung RS, Gerber D, Bloom RD. Proceedings of Consensus Conference on Simultaneous Liver Kidney Transplantation (SLK). Am J Transplant. 2008;8(11):2243-2251. doi:10.1111/j.1600-6143.2008.02416.x

64. Bray BD, Boyd J, Daly C, et al. How safe is renal replacement therapy? A national study of mortality and adverse events contributing to the death of renal replacement therapy recipients. Nephrol Dial Transplant. 2014;29(3):681-687. doi:10.1093/ndt/gft197

65. Krag A, Bendtsen F, Henriksen JH, Moller S. Low cardiac output predicts development of hepatorenal syndrome and survival in patients with cirrhosis and ascites. Gut. 2010;59(1):105-110. doi:10.1136/gut.2009.180570
66. Newton JL, Allen J, Kerr S, Jones DE. Reduced heart rate variability and baroreflex sensitivity in primary biliary cirrhosis. Liver Int. 2006;26(2):197-202. doi:10.1111/j.1478-3231.2005.01214.x

67. Acevedo J, Fernandez J, Prado V, et al. Relative adrenal insufficiency in decompensated cirrhosis: relationship to short-term risk of severe sepsis, hepatorenal syndrome, and death. Hepatology. 2013;58 (5):1757-1765. doi:10.1002/hep.26535

68. Bernardi M, Moreau R, Angeli P, Schnabl B, Arroyo V. Mechanisms of decompensation and organ failure in cirrhosis: from peripheral arterial vasodilation to systemic inflammation hypothesis. J Hepatol. 2015;63(5):1272-1284. doi:10.1016/j.jhep.2015.07.004

69. de Cleva R, Silva FP, Zilberstein B, Machado DJ. Acute renal failure due to abdominal compartment syndrome: report on four cases and literature review. Rev Hosp Clin Fac Med Sao Paulo. 2001;56 (4):123-130. doi:10.1590/S0041-87812001000400006

70. Sola-Vera J, Minana J, Ricart E, et al. Randomized trial comparing albumin and saline in the prevention of paracentesis-induced circulatory dysfunction in cirrhotic patients with ascites. Hepatology. 2003;37(5):1147-1153. doi:10.1053/jhep.2003.50169

71. Bernardi M, Caraceni P, Navickis RJ, Wilkes MM. Albumin infusion in patients undergoing large-volume paracentesis: a meta-analysis of randomized trials. Hepatology. 2012;55(4):1172-1181. doi:10.1002/ hep. 24786

72. Fernandez J, Navasa M, Planas R, et al. Primary prophylaxis of spontaneous bacterial peritonitis delays hepatorenal syndrome and improves survival in cirrhosis. Gastroenterology. 2007;133 (3):818-824.

73. Salerno F, Navickis RJ, Wilkes MM. Albumin infusion improves outcomes of patients with spontaneous bacterial peritonitis: a meta-analysis of randomized trials. Clin Gastroenterol Hepatol. 2013;11(2):123-30.e1. doi:10.1016/j.cgh.2012.11.007

74. Guevara M, Terra C, Nazar A, et al. Albumin for bacterial infections other than spontaneous bacterial peritonitis in cirrhosis. A randomized, controlled study. J Hepatol. 2012;57(4):759-765. doi:10.1016/j.jhep.2012.06.013

75. Thevenot T, Bureau C, Oberti F, et al. Effect of albumin in cirrhotic patients with infection other than spontaneous bacterial peritonitis. A randomized trial. J Hepatol. 2015;62(4):822-830. doi:10.1016/j. jhep.2014.11.017

76. Busk TM, Bendtsen F, Moller S. Hepatorenal syndrome in cirrhosis: diagnostic, pathophysiological, and therapeutic aspects. Expert Rev Gastroenterol Hepatol. 2016;10(10):1153-1161. doi:10.1080/ 17474124.2016.1196132

77. Mandorfer M, Bota S, Schwabl P, et al. Nonselective $\beta$ blockers increase risk for hepatorenal syndrome and death in patients with cirrhosis and spontaneous bacterial peritonitis. Gastroenterology. 2014;146(7):1680-90.e1. doi:10.1053/j.gastro.2014.03.005

78. de Franchis R. Expanding consensus in portal hypertension: report of the Baveno VI Consensus Workshop: stratifying risk and individualizing care for portal hypertension. J Hepatol. 2015;63(3):743-752. doi:10.1016/j.jhep.2015.05.022

79. Aithal GP, Palaniyappan N, China L, et al. Guidelines on the management of ascites in cirrhosis. Gut. 2021;70(1):9-29.

80. European Association for the Study of the Liver. EASL clinical practice guidelines on nutrition in chronic liver disease. $J$ Hepatol. 2019;70(1):172-193.

81. Acevedo JG, Cramp ME. Hepatorenal syndrome: update on diagnosis and therapy. World J Hepatol. 2017;9(6):293-299. doi:10.4254/wjh. v9.i6.293 


\section{Publish your work in this journal}

Clinical and Experimental Gastroenterology is an international, peerreviewed, open access, online journal publishing original research, reports, editorials, reviews and commentaries on all aspects of gastroenterology in the clinic and laboratory. This journal is indexed on American Chemical Society's Chemical Abstracts Service (CAS).
The manuscript management system is completely online and includes a very quick and fair peer-review system, which is all easy to use. Visit http://www.dovepress.com/testimonials.php to read real quotes from published authors. 